TI 2018-079/I

Tinbergen Institute Discussion Paper
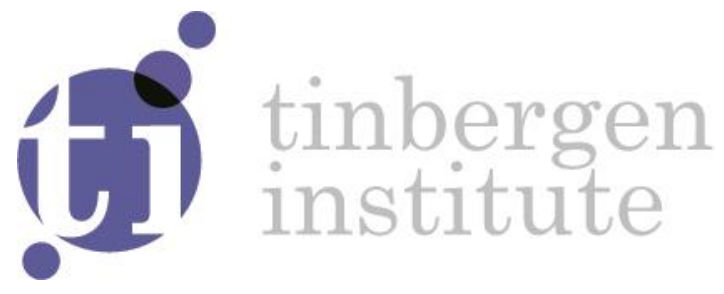

\title{
Reflection for higher order risk preferences
}

Han (H.) Bleichrodt ${ }^{1,2}$

Paul van Bruggen ${ }^{2}$

\footnotetext{
${ }^{1}$ Australian National University

2 Erasmus School of Economics
} 
Tinbergen Institute is the graduate school and research institute in economics of Erasmus University Rotterdam, the University of Amsterdam and VU University Amsterdam.

Contact: discussionpapers@tinbergen.nl

More TI discussion papers can be downloaded at http://www.tinbergen.nl

Tinbergen Institute has two locations:

Tinbergen Institute Amsterdam

Gustav Mahlerplein 117

1082 MS Amsterdam

The Netherlands

Tel.: +31(0)205984580

Tinbergen Institute Rotterdam

Burg. Oudlaan 50

3062 PA Rotterdam

The Netherlands

Tel.: +31(0)10408 8900 


\title{
Reflection for higher order risk preferences*
}

\author{
Han Bleichrodt ${ }^{\mathrm{a}}$ and Paul van Bruggen ${ }^{\mathrm{b}}$ \\ ${ }^{a, b}$ Erasmus School of Economics and Tinbergen Institute, Rotterdam \\ ${ }^{a}$ Research School of Economics, Australian National University, Canberra
}

October 23, 2018

\begin{abstract}
Higher order risk preferences are important determinants of economic behaviour. We apply behavioural insights to this topic: we measure higher order risk preferences for pure gains and pure losses by controlling the reference point. We find a reflection effect not only for second order risk preferences, as in Kahneman and Tversky (1979), but also for higher order risk preferences: we find risk aversion, prudence and intemperance for gains, but risk loving preferences, imprudence and temperance for losses. The risk aversion and intemperance for gains and the imprudence for losses is evidence against a preference for combining good with bad or good with good, which previous theoretical and empirical results suggest may underlie higher order risk preferences.
\end{abstract}

JEL classification: C91, D81, D91

Keywords: Risk Apportionment; Higher Order Risk Preferences; Risk Aversion; Prudence; Temperance; Reference Dependence.

\section{Introduction}

Where risk aversion has been the cornerstone of the economic analysis of decision making under risk since the 1950s, only relatively recently have higher order risk preferences been receiving the attention they deserve. Although prudence as a concept has been used in the analysis of intertemporal risk preferences since Leland (1968), Sandmo (1970) and Drèze and Modigliani (1972), specifically as

*Erasmus School of Economics and Tinbergen Institute, Erasmus University, 3000 DR Rotterdam, The Netherlands. ${ }^{a}$ bleichrodt@ese.eur.nl. ${ }^{b}$ p.vanbruggen@ese.eur.nl, corresponding author.

The experiment reported in this paper was partially funded by a contribution from the Erasmus Research Institute of Management (ERIM). 

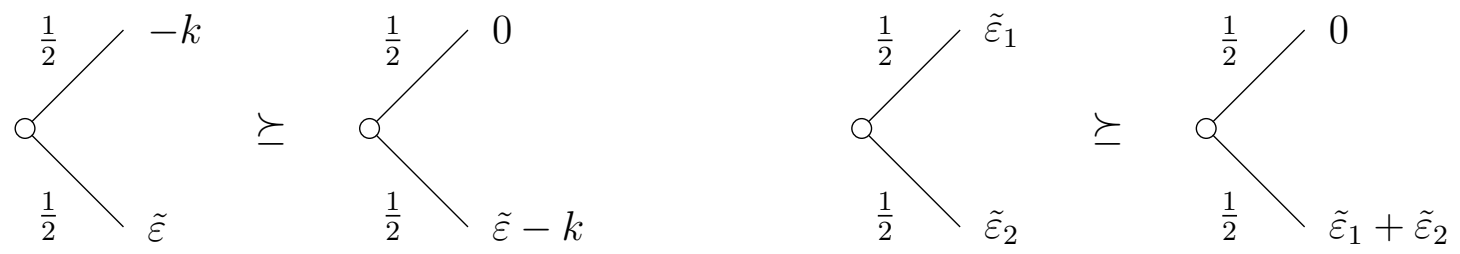

Figure 1: Eeckhoudt and Schlesinger's (2006) definitions of prudence (left) and temperance (right), for all $k>0$ and all zero-mean random variables $\tilde{\varepsilon}$, $\tilde{\varepsilon}_{1}$ and $\tilde{\varepsilon}_{2}$.

a precautionary savings motive, the term 'prudence' was only coined by Kimball (1990). Temperance was introduced even more recently: the concept by Pratt and Zeckhauser (1987) and the term by Kimball (1992). Prudence is equivalent to aversion to downside risks (Menezes et al., 1980) and temperance relates to whether the presence of an independent background risk makes a person more risk averse (Gollier and Pratt, 1996). Model-free definitions of prudence and temperance proposed by Eeckhoudt and Schlesinger (2006) are illustrated in Figure 1. ${ }^{1}$

The importance of these preferences has been shown in such different contexts as insurance in the presence of background risks (Fei and Schlesinger, 2008), auctions (Eső and White, 2004), and probabilistic insurance and investments in self-protection, which reduce the probability of incurring a loss but do not take away this probability completely (Eeckhoudt and Gollier, 2005; Peter, 2017). Evidence of higher order risk preferences has been found with field data, see e.g. Browning and Lusardi (1996) and Carroll and Samwick (1998), as well as in experiments, see the review article by Trautmann and Van de Kuilen (2018).

In this paper, we apply behavioural insights to the study of these higher order risk preferences. In his Prize Lecture on receiving the Bank of Sweden Prize in Economic Sciences in Memory of Alfred Nobel, Daniel Kahneman called reference dependence 'the core of prospect theory' (Kahneman, 2003, p. 1457). Yet reference dependence, which leads to a reflection of risk aversion over the gain and loss domain, has not been thoroughly investigated or controlled for in existing studies. We measure higher order risk preferences while directly controlling the reference point to separate gains and losses. We control the reference point by giving subjects an endowment before the experiment.

Separating gains and losses allows us to investigate whether higher order risk preferences, like risk aversion, reflect between the gain and loss domain. This is important for two reasons. The first is external validity. Preferences measured

\footnotetext{
${ }^{1}$ Higher order risk preferences have been extended to multivariate risk preferences (Eeckhoudt et al., 2007), to ambiguity (Baillon, 2017) and to time (Ebert, 2016). For an introduction on higher-order risk preferences, see Eeckhoudt and Schlesinger (2013).
} 
under gains in an experiment may be a poor predictor of behaviour in the field for choices which naturally involve losses, such as insurance decisions. Decision makers who are measured to be prudent under gains may demand probabilistic insurance despite a prediction based on observed prudence that they would not purchase such insurance (Eeckhoudt and Gollier, 2005).

The second reason is that the domain will influence decisions dependent on higher order risk preferences. In a financial crisis, when their portfolios are deeply in the loss domain, investors may come to prefer downside risks and may behave less risk averse when background risk increases even if they have the reverse preferences in more usual situations.

Separating gains and losses means we measure preferences without loss aversion, which affects choices for lotteries that mix gains and losses. For example, if subjects take the highest possible outcome they are sure to get (the MaxMin) as the reference point, loss aversion will bias responses toward risk risk aversion, prudence and temperance. ${ }^{2}$ Thus, we can test the hypothesis of a preference for combining good with bad or for combining good with good without the confounding effects of loss aversion. Eeckhoudt et al. (2009) and Crainich et al. (2013) show that these simple preferences may underlie higher order risk preferences, in which case decision makers who are risk averse should be temperate, whereas those who are risk loving should be intemperate, and both should be prudent.

The importance of investigating the influence of the domain on higher order risk preferences was already recognised by Deck and Schlesinger (2010) and Maier and Rüger (2012). ${ }^{3}$ However, they do not directly control the reference point, which is needed to separate gains and losses. Deck and Schlesinger (2010) rewrite lotteries so fixed payments are presented as fixed deductions. Maier and Rüger (2012) have subjects return to the lab and lose part of their earlier winnings, but cannot control what happens between sessions. Whether a reference point is induced successfully is ultimately an empirical question. Reproducing reference dependence of risk aversion demonstrates that outcomes intended to involve gains and losses are perceived as such, but neither study does so. With out design, we replicate reference dependence of risk aversion.

\footnotetext{
${ }^{2}$ With such a reference point, the worst outcome between two lotteries is perceived as a loss. This is always an outcome of the option which indicates the risk loving preferences, imprudence or intemperance, decreasing their relative attractiveness.

${ }^{3}$ Using hypothetical choices, Attema et al. (2017) find risk aversion and prudence for gains and risk neutrality and prudence neutrality for losses.
} 
We also measure higher order risk preferences with lotteries for which the branches in Figure 1 involve probabilities smaller than 0.5. ${ }^{4}$ We extend the definitions of Eeckhoudt and Schlesinger (2006) to such small probability lotteries and show that the results of Eeckhoudt et al. (2009) apply to them.

We find a reflection effect for higher order risk preferences: under both gain treatments, the majority of choices are risk averse, prudent and intemperate, whereas under losses the majority of choices are risk loving, imprudent and temperate. The imprudence we find for losses and the combination of risk aversion and intemperance for gains is evidence against the hypothesis that a preference for combining good with bad or good with good underlies higher order risk preferences. We find similar behaviour for small probability lotteries and the usual 50-50 lotteries.

\section{Theoretical background}

Eeckhoudt and Schlesinger (2006) define higher order risk preferences through simple lottery pairs. Let $[x, y]$ denote the lottery that gives outcome $x$ with probability 0.5 and outcome $y$ with probability 0.5 . Let $\succeq$ denote the decision maker's preference relation. Risk aversion is defined as the preference $[-k,-r] \succeq$ $[0,-k-r]$ for all wealth levels and for all $k, r>0$. Eeckhoudt and Schlesinger (2006) name such an attitude risk apportionment of order 2. A decision maker is risk loving if the reverse preferences hold. To define prudence (risk apportionment of order 3 ), the fixed deduction $-r$ is replaced by a zero-mean nondegenerate random variable $\tilde{\varepsilon}$ (see Figure 1 ). The decision maker is prudent if $[-k, \tilde{\varepsilon}] \succeq$ $[0, \tilde{\varepsilon}-k]$ for all wealth levels, for all $k>0$ and for all zero-mean, non-degenerate random variables $\tilde{\varepsilon}$. The decision maker is imprudent if the reverse preferences hold. Temperance (risk apportionment of order 4) is defined by replacing $-k$ by another independent random variable. The decision maker is temperate if $\left[\tilde{\varepsilon}_{1}, \tilde{\varepsilon}_{2}\right] \succeq\left[0, \tilde{\varepsilon}_{1}+\tilde{\varepsilon}_{2}\right]$ for all wealth levels and for all zero-mean, non-degenerate and independent random variables $\tilde{\varepsilon}_{1}$ and $\tilde{\varepsilon}_{2}$. If the reverse preferences hold the risk attitude is called intemperance. Risk attitudes of orders higher than 4 can be defined through similar procedures, but we do not study those attitudes in this paper.

\footnotetext{
${ }^{4}$ Ebert and Wiesen $(2011,2014)$ use skewed zero-mean lotteries ( $\tilde{\varepsilon}$ in Figure 1), which therefore involve probabilities smaller than 0.5 , but there the effect of smaller probabilities is confounded by a preference for skewness.
} 
Eeckhoudt et al. (2009) show how stochastic dominance preferences lead to risk apportionment of any order. They show that if $\tilde{x}_{i}$ dominates $\tilde{y}_{i}, i=a, b$, through $i$ th order stochastic dominance, then the 50-50 lottery $\left[\tilde{x}_{a}+\tilde{y}_{b}, \tilde{x}_{b}+\tilde{y}_{a}\right]$ dominates $\left[\tilde{y}_{a}+\tilde{y}_{b}, \tilde{x}_{a}+\tilde{x}_{b}\right]$ through $(a+b)$ th stochastic dominance. Stochastic dominance preferences thus imply a preference for combining the 'good' lottery with the 'bad' lottery, and contain risk apportionment preferences as defined by Eeckhoudt and Schlesinger (2006) as a special case. A preference for combining good with bad thus leads to a combination of risk aversion, prudence, and temperance, etc.

Crainich et al. (2013) apply this logic to decision makers who prefer combining good with good and show that this leads to a combination of risk loving, prudent and intemperate preferences. It follows that indifference toward combining good with bad and good with good leads to risk neutrality, prudence neutrality, and temperance neutrality. The results above also hold when all final outcomes are only in the domain of gains (relative to some reference point) or only in the domain of losses. We can therefore test for these implications separately for both domains to see if there are behavioural differences between them.

Because we study preferences over lotteries involving probabilities different from 50-50 we need to extend the above definitions. Let $(p: x, p: y, 1-2 p: z)$ denote the lottery that gives the outcome $x$ or $y$ with probability $p$ and outcome $z$ with probability $1-2 p$. Risk aversion is then defined as

$$
(p:-k, p:-r, 1-2 p: c) \succeq(p: 0, p:-k-r, 1-2 p: c)
$$

prudence as

$$
(p:-k, p: \tilde{\varepsilon}, 1-2 p: c) \succeq(p: 0, p: \tilde{\varepsilon}-k, 1-2 p: c)
$$

and temperance as

$$
\left(p: \tilde{\varepsilon}_{1}, p: \tilde{\varepsilon}_{2}, 1-2 p: c\right) \succeq\left(p: 0, p: \tilde{\varepsilon}_{1}+\tilde{\varepsilon}_{2}, 1-2 p: c\right)
$$

for all $p \in[0,1]$, all $k, r>0$, all $c$, all independent zero-mean risks $\tilde{\varepsilon}$, $\tilde{\varepsilon}_{1}$ and $\tilde{\varepsilon}_{2}$ and all wealth levels. Risk loving preferences, imprudence, and intemperance are defined as the reverse preferences. Under expected utility these extended definitions are equivalent to the usual definitions of risk aversion, prudence and temperance (necessity follows from the independence axiom and sufficiency follows from their definition). Furthermore, the results of Eeckhoudt et al. (2009) apply to these extended definitions: if $\left[\tilde{x}_{a}+\tilde{y}_{b}, \tilde{x}_{b}+\tilde{y}_{a}\right]$ dominates $\left[\tilde{y}_{a}+\tilde{y}_{b}, \tilde{x}_{a}+\tilde{x}_{b}\right]$ through $(a+b)$ th 
stochastic dominance, then the probabilistic mixture $\left(\lambda:\left[\tilde{y}_{a}+\tilde{y}_{b}, \tilde{x}_{a}+\tilde{x}_{b}\right], 1-\lambda: c\right)$ also dominates $\left(\lambda:\left[\tilde{y}_{a}+\tilde{y}_{b}, \tilde{x}_{a}+\tilde{x}_{b}\right], 1-\lambda: c\right)$ through $(a+b)$ th stochastic dominance (a proof is in Appendix A).

\section{Experiment design}

We measure higher order risk preferences in three treatments, two involving gains (i.e. with all outcomes positive additions to the initial payment) and one involving losses (with all outcomes negative additions to the initial payment). To induce a strong reference point, subjects face both gains and losses relative to their initial endowment; we therefore have a within-subject design for testing gains and losses. The two gain treatments involve a between-subject design (subjects were assigned randomly to either gain treatment). The 50-50 gain treatment involves the usual 50-50 lotteries, the small probability gain treatment involves the small probability lotteries discussed in Section 2. The small probability treatment allows us to offer the possibility of sizeable gains. For the loss treatment we measure preferences using the usual 50-50 lotteries. The small probability definitions cannot be used together with bigger losses, because losses exceeding the initial endowment would lead to negative earnings. For each of the three treatments we measure three higher order risk attitudes (risk aversion, prudence, and temperance). Thus we have nine treatment-risk attitude pairs in total.

To study the effects of reference-dependence, it is important to control the reference point. To this end, subjects were given a $€ 15$ endowment at the start of the experiment. They were told that this endowment was their payment for participating in the experiment, that they could gain additional money or lose part of it, and that it was equal to the expected value of participating. Throughout our analysis we assume that subjects take the initial endowment as their reference point. This is a common assumption in the literature and is consistent with a reference point based on rational expectations (Köszegi and Rabin, 2006) or based on the status quo. Baillon et al. (2017a) find evidence for subjects taking the status quo as their reference point and Etchart-Vincent and l'Haridon (2011) find that behaviour is similar under losses from an initial endowment and losses out of subjects' own pockets.

The tasks are listed in Tables 5, 6 and 7 in Appendix D and a screenshot of one of the tasks can be found in Appendix C. Lotteries are presented in compound form in all tasks. We use compound lotteries because it most clearly presents the choice as between combining 'good with bad' or 'good with good'. Haering et al. 
(2017) find that prudence and temperance are stronger for compound lotteries than for reduced-form lotteries. Deck and Schlesinger (2017) investigate presenting lotteries in compound form and in reduced form and find that while aggregate patterns are not much different, individuals have different preferences between the different formats.

Probabilities are presented as drawing a coloured token from a bag with 100 coloured tokens. To avoid mixing gains and losses, outcomes are chosen in such a way that, relative to the initial payment, they are always negative in the loss treatment and always positive in the gain treatments. There are no zero outcomes (relative to the initial $€ 15$ ) to prevent possible effects such as loss and zero avoidance from influencing responses. Subjects were presented with 12 tasks for each risk attitude in a given treatment. The relatively large number of tasks allows us to distinguish subjects who are indifferent (or confused) from those who have a clear attitude without having to measure willingness-to-pay. Measuring willingness-topay would complicate the procedure while the binary choices are already quite complex, especially for temperance.

The experiment was performed in the ESE-econlab. Subjects were randomly selected from the ESE-econlab subject pool, which consists of people who have registered to participate in experiments, and invited to sign up for sessions through an automated email system. 122 subjects participated in the experiment and made a total of 8784 choices. Upon entering the lab, subjects were given an envelope containing $€ 15$ and assigned a seat in a cubicle. Subjects started the experiment and left the lab at the same time and made their choices on a computer. In the instructions, they were informed that one of their choices in the experiment would be implemented for real, which would result in winning additional money or losing part of their initial payment, and that their expected earnings were equal to the amount they had been given. The instructions furthermore contained an explanation of the possible outcomes of a lottery similar to one of the more complicated lotteries used in the experiment and subjects were asked three comprehension questions which had to be answered correctly before they could proceed to the incentivised tasks. In addition, subjects were asked to answer a (non-incentivised) practice question before getting to the incentivised tasks to allow them to become familiar with the interface.

Each subject was randomly assigned to either the small probability gain treatment or the 50-50 gain treatment by the software and all participated in the loss treatment. Every subject thus participated in a total of two treatments, one loss treatment and one gain treatment. The tasks of a particular higher order 
risk concept for a given treatment were presented together and the order of the tasks within such a block of tasks was randomised, as was the order of the blocks themselves. Thus, whether a subject first faced a loss or a gain task was determined randomly. The location, left or right, of the option that satisfies risk apportionment was randomised for each subject and for each task. Subjects could go back to previous tasks in the same block of questions and change their choices if they so wanted. ${ }^{5}$ Subjects could only continue to the next task after making a choice in the current one, which they could do by clicking on the lottery they preferred. To indicate the choice they had made, the selected option would then be highlighted.

After answering all questions in the experiment, subjects were asked one by one to come to the front desk to play one of their choices for real. Subjects were asked to roll a six-sided die to select one of the six blocks of tasks, three of which measured preferences under losses and three of which measured preferences under gains, and a twelve-sided die to select according to which of the twelve choices in that block they would be paid. The subject would then draw a coloured, plastic token from an opaque bag with a composition of tokens corresponding to that described in the selected task. Composing the bag was done in full view of the first subject in each session for whom that bag was needed and subjects who came thereafter could inspect the bag if they wished. Some subjects had to draw tokens from more than one bag. Depending on the final outcome, the subject would then be paid in addition to their initial $€ 15$ payment or have to give up part of it. The average earnings of subjects were $€ 15.28$ and the total duration of a session including the payment procedure was less than one hour.

\section{Results}

\subsection{Aggregate behaviour, non-parametric methods}

Figures 2 and 3 show the number of times subjects chose in agreement with risk aversion, prudence, and temperance in the loss treatment (Figure 2) and in the gain treatments (Figure 3). For all risk attitudes in all treatments the mode is either 12 or 0 choices consistent with risk apportionment (risk aversion, prudence, or temperance), meaning fully consistent choices for or against risk apportionment, and in most cases the second most common outcome is another 12 choices for the reverse higher order risk attitude. This consistency is reassuring considering

\footnotetext{
${ }^{5} 2.5 \%$ of all choices were revised by subjects in the experiment.
} 

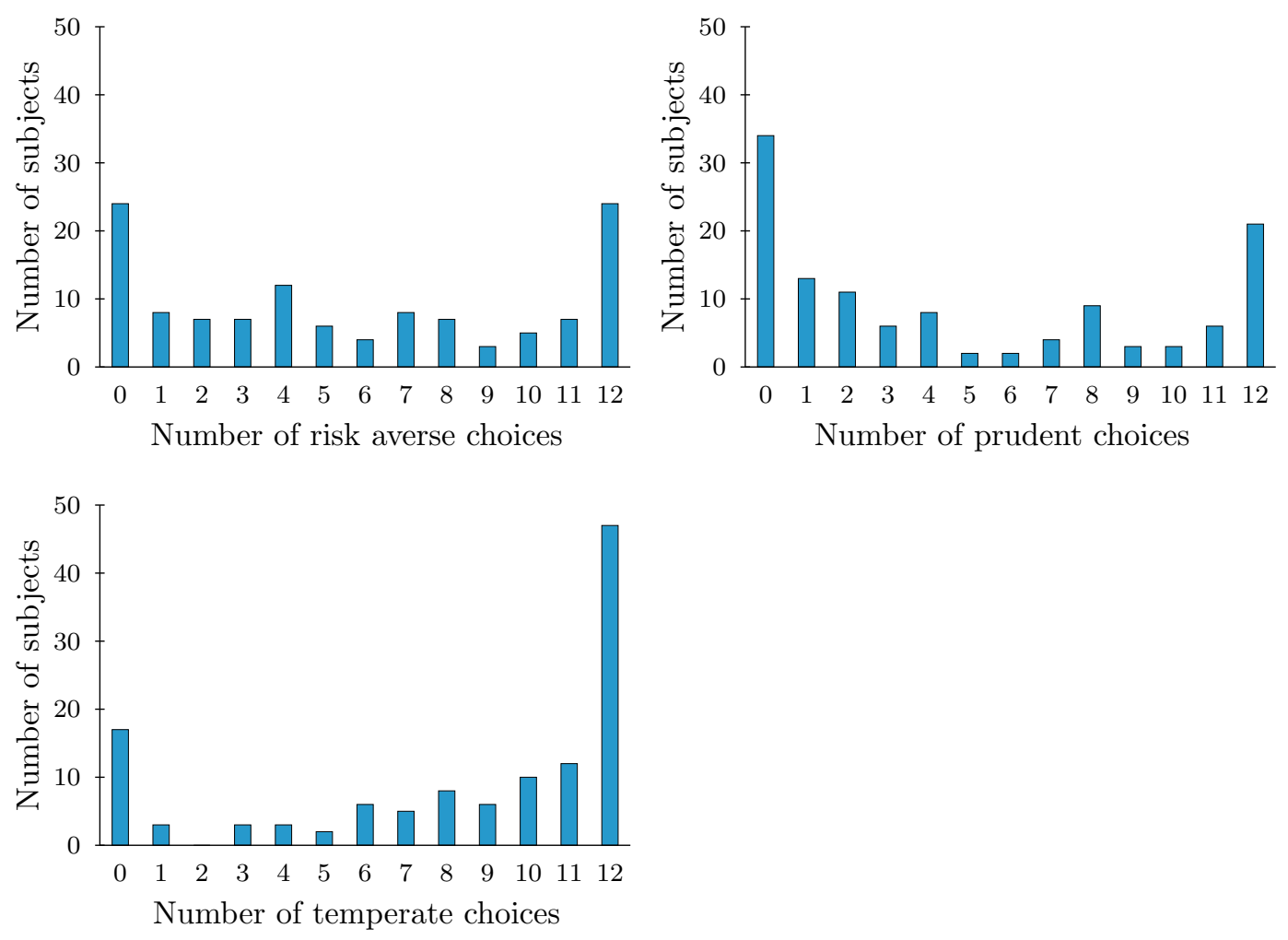

Figure 2: Histograms of choices in the loss treatment.

the involved choices subjects need to make when measuring higher order risk preferences.

The data appears to become noisier as the order of the tasks increases, at least for gains. Taking the distance from 6 choices for the option satisfying risk apportionment as an ordinal measure of consistency, ${ }^{6}$ we find a negative Spearman rank correlation between the risk order and consistency for 50-50 gains ( $\rho-0.213$, $p$-value 0.004$)$ and small probability gains $(\rho-0.157, p$-value 0.033$)$. The small probability gains data is more consistent than the 50-50 gains data: the average distance from random choice is 4.57 for 50-50 gains and 5.05 for small probability gains for second order tasks (Mann-Whitney-U test, $p$-value 0.035 ), respectively 3.95 and 4.84 for third order tasks ( $p$-value 0.011), and 3.42 and 4.24 for fourth order tasks ( $p$-value 0.034). For losses, we find that the data becomes slightly less noisy as the order of the tasks increases ( $\rho 0.117, p$-value 0.026$)$.

Figures 2 and 3 suggest a reflection effect of higher risk attitudes: while the patterns are very similar for the two gain treatments, they are markedly different for the loss treatment. This reflection effect is also visible in Table 1, which shows

\footnotetext{
${ }^{6}$ This is, on average, the number of choices made for the options satisfying risk apportionment by a decision maker choosing randomly.
} 

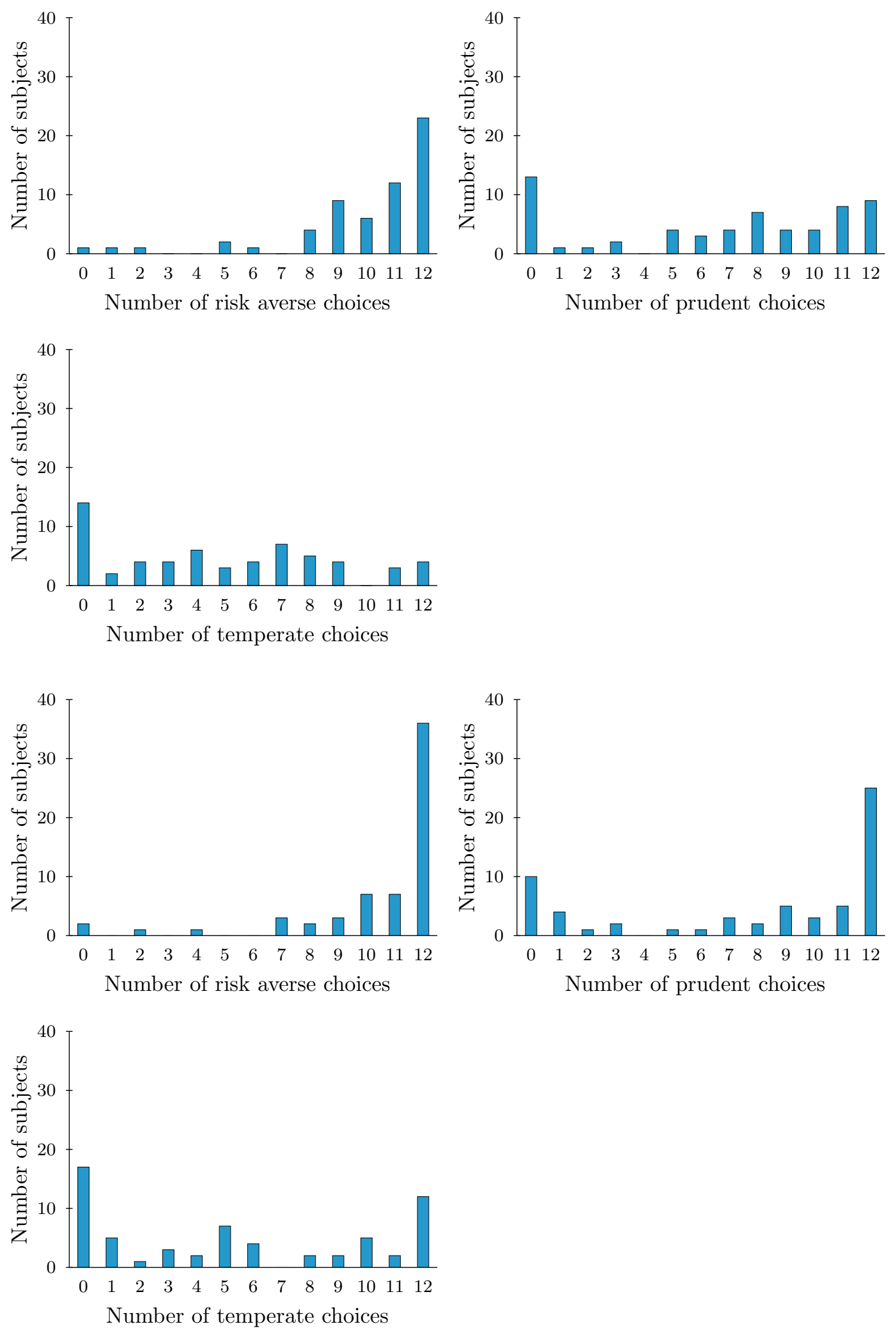

Figure 3: Histograms of choices in the 50-50 gain (top) and small probability (bottom) treatment. 
Table 1: Aggregate choices by treatment and higher order risk preference

\begin{tabular}{lccc}
\hline & $\begin{array}{c}\text { Risk averse } \\
\text { choices }(\%)\end{array}$ & $\begin{array}{c}\text { Prudent choices } \\
(\%)\end{array}$ & $\begin{array}{c}\text { Temperate choices } \\
(\%)\end{array}$ \\
\hline Losses & $47.7^{*}$ & $39.8^{* * *}$ & $69.6^{* * *}$ \\
$50-50$ gains & $83.3^{* * *}$ & $56.0^{* * *}$ & $40.4^{* * *}$ \\
Small probability gains & $87.2^{* * *}$ & $65.9^{* * *}$ & $44.8^{* * *}$ \\
\hline \multicolumn{2}{l}{ Asterisks indicate significance (binomial test) at the $10 \%\left(^{*}\right), 5 \%\left(^{* *}\right)$ and $1 \%\left(^{* * *}\right)$ level. }
\end{tabular}

Asterisks indicate significance (binomial test) at the $10 \%\left({ }^{*}\right), 5 \%\left({ }^{* *}\right)$ and $1 \%\left({ }^{* * *}\right)$ level.

the proportion of choices consistent with risk apportionment in each of the three treatments. ${ }^{7}$ We find risk aversion and prudence in both gain treatments, which is consistent with the usual findings in the literature, and weak (if significant) intemperance, which is consistent with the findings of Deck and Schlesinger (2010) and Baillon et al. (2017b), but not with the results of Ebert and Wiesen (2014), Deck and Schlesinger (2014) and Noussair et al. (2014), who find modest temperance in the aggregate. For losses, we find slightly risk loving preferences, imprudence and strong temperance in the aggregate. The differences in the number of risk averse choices between the loss treatment and the 50-50 gain treatment (Wilcoxon signed rank test, $p$-value $<0.001)$ and the small probability gain treatment ( $p$-value $<0.001)$ are significant, as are the difference in the number of prudent choices between the loss treatment and the gain treatments $(p$-values 0.003 and $<0.001$ for for 50-50 and small probability gains, respectively) and the greater frequency of temperate choices in the loss treatment compared to the gain treatments ( $p$-values $<0.001$ and $<0.001){ }^{8}$

A preference for combining good with bad or good with good leads to three possible combinations of risk attitudes (see Section 2): those who are risk averse, prudent and temperate, those who are risk loving, prudent and intemperate, and those who are risk neutral, prudence neutral and temperance neutral. At the aggregate level, we do not find evidence in support of a preference for combining good with bad or good with good underlying higher order risk preferences. In the gain treatments, which induce the strongest risk aversion, we find the weakest temperance, and for losses we find imprudence as the most common preference.

\footnotetext{
${ }^{7}$ When measuring types of preferences, as in this study, reflection indicates a reversal from one type to the opposite type, i.e. from risk apportionment to the reverse preference, or vice versa.

${ }^{8}$ Results when testing for order effects were not significant, both for whether the first block in the experiment involved gains or losses, and for whether the first block for a given risk attitude concerned gains or losses.
} 
Table 2: Rank correlations between risk averse, prudent and temperate choices ( $p$-values in parentheses)

\begin{tabular}{llcc}
\hline & & Risk averse choices & Prudent choices \\
\hline Losses & Prudent choices & 0.135 & \\
& & $(0.137)$ & -0.088 \\
& Temperate choices & -0.050 & $(0.335)$ \\
\hline 50-50 gains & Prudent choices & -0.037 & \\
& & $(0.781)$ & 0.103 \\
& Temperate choices & -0.030 & $(0.435)$ \\
\hline Small probability & & $(0.823)$ & \\
gains & Prudent choices & 0.377 & 0.150 \\
& & $(0.003)$ & $(0.246)$ \\
\hline
\end{tabular}

\subsection{Individual behaviour, non-parametric methods}

Within treatments, we can test for the correlation between the various higher order risk preferences. Spearman correlation coefficients and $p$-values are reported in Table 2 for the three treatments. A preference for combining good with bad or good with good predicts that the number of temperate choices is positively correlated with the number of risk averse choices, but the number of prudent choices is not. The only statistically significant correlation in the data, however, is between prudence and risk aversion for the small probability gain treatment. The correlations between choices for the risk averse options and choices for the intemperate options are statistically insignificant for all treatments.

A caveat to the tests of the correlations in Table 2 is that large numbers of indifferent subjects would push any positive correlation toward zero. Many subjects chose the risk averse, prudent, or temperate option no more than 2 times (out of 12) or at least 10 times, and the probability of doing so when choosing randomly is slightly less than $4 \%$. We therefore classify subjects accordingly. The remaining subjects, who chose the risk averse, prudent, or temperate option between 3 and 9 times, we classify as risk neutral, prudence neutral, and temperance neutral. ${ }^{9}$ The frequencies of types are reported in Tables 8, 9 and 10 in Appendix E.

\footnotetext{
${ }^{9}$ This classification is consistent with the maximum likelihood estimations of the proportion of each type which we present below. We also considered the choice patterns of perfectly consistent subjects only. These looked qualitatively similar.
} 
Using this classification we also find little evidence that fourth order risk attitudes depend on second order risk attitudes. For losses and 50-50 gains, the patterns of temperance do not appear to depend on second order risk preferences, and a Fisher's exact test ( $p$-value 0.626 , respectively 0.800 ) cannot reject that the patterns are the same. The distribution of fourth order risk preferences does depend on second order risk preferences for the small probability gain treatment ( $p$-value 0.002 ), but this is mostly driven by the relatively large number of temperance neutral subjects among the group of risk neutral individuals. ${ }^{10}$

\subsection{Aggregate behaviour, maximum likelihood estimation}

The previous results are based on an informal argument that choices at the extremes are unlikely to be the result of a subject choosing randomly between the options. To model this explicitly, we perform maximum likelihood estimation on the data. We estimate a mixed binomial distribution for each order of risk apportionment, with $\pi_{s}$ the proportion of decision makers who satisfy risk apportionment for that particular order, $\pi_{o}$ the proportion of decision makes with the opposite risk attitude, and $\pi_{n}$ the proportion of neutral or indifferent decision makers.

We allow for types with strict preferences to make errors. In any task, subjects who satisfy risk apportionment have a probability $\eta$ of choosing the option that does not indicate risk apportionment, which is allowed to differ from the error rate $\delta$ for those who have the opposite preference. We assume that the probability that an indifferent decision maker chooses the option that indicates risk apportionment is equal to $1 / 2 .{ }^{11}$ The error rates are estimated separately for each higher order risk preference because the lotteries become increasingly complex as the order of the risk preference increases, and it is important to be able to distinguish risk preferences from a tendency toward random choice. Note that noisy behaviour will also be captured by the proportion of decision makers with 'neutral' risk attitudes: a decision maker who is confused or inattentive may simply choose (almost) randomly. The parameter values, estimated using numerical methods, are presented in Table 3.

The estimated proportions support the results from the non-parametric analysis. For losses, there are slightly more risk lovers than risk averters, there is strong imprudence, and strong temperance. For 50-50 gains and small probability gains,

\footnotetext{
${ }^{10}$ When excluding neutral types, the difference is not statistically significant ( $p$-value 0.233 ).

${ }^{11}$ The position (left or right) of the lottery satisfying risk apportionment was randomised, so even an indifferent subject who always chooses the left or right option would choose the option satisfying risk apportionment with a probability of 0.5 .
} 
Table 3: Estimated parameter values for different types of higher order risk preferences

\begin{tabular}{llccccc}
\hline Order & Treatment & $\hat{\pi}_{s}$ & $\hat{\pi}_{n}$ & $\hat{\pi}_{o}$ & $\hat{\eta}$ & $\hat{\delta}$ \\
\hline 2 & Losses & 0.29 & $\underline{0.39}$ & 0.33 & 0.04 & 0.05 \\
& 50-50 gains & $\underline{0.86}$ & 0.09 & 0.05 & 0.09 & 0.08 \\
& Small probability gains & $\underline{0.83}$ & 0.13 & 0.04 & 0.04 & 0.04 \\
3 & Losses & 0.24 & 0.26 & $\underline{0.50}$ & 0.03 & 0.06 \\
& 50-50 gains & $\underline{0.40}$ & 0.37 & 0.23 & 0.09 & 0.01 \\
& Small probability gains & $\underline{0.55}$ & 0.21 & 0.24 & 0.03 & 0.04 \\
4 & Losses & $\underline{0.58}$ & 0.26 & 0.16 & 0.04 & 0.01 \\
& 50-50 gains & 0.12 & $\underline{0.57}$ & 0.32 & 0.04 & 0.04 \\
& Small probability gains & 0.31 & 0.33 & $\underline{0.37}$ & 0.06 & 0.02 \\
\hline
\end{tabular}

Underlines indicate the mode.

Table 4: Likelihood ratios and $p$-values for the test $H_{0}: \pi_{s}=\pi_{o}, H_{a}: \pi_{s} \neq \pi_{o}$

\begin{tabular}{llcc}
\hline Order & Treatment & LR & $p$-value \\
\hline 2 & Losses & 0.31 & 0.577 \\
& 50-50 gains & 38.21 & $<0.001$ \\
& Small probability gains & 52.38 & $<0.001$ \\
3 & Losses & 10.58 & 0.001 \\
& 50-50 gains & 2.38 & 0.123 \\
& Small probability gains & 7.08 & 0.008 \\
4 & Losses & 29.07 & $<0.001$ \\
& 50-50 gains & 5.17 & 0.023 \\
& Small probability gains & 0.34 & 0.559 \\
\hline
\end{tabular}

there is strong risk aversion, strong prudence, and some intemperance. Likelihood ratio tests, reported in Table 4, show that six of these differences are statistically significant. Only the risk loving attitude for losses, prudence for 50-50 gains, and intemperance for small probability gains are not significantly more common than the opposite attitude: in these cases we cannot reject the null hypothesis that $\pi_{s}=\pi_{o}$ against the alternative hypothesis that $\pi_{s} \neq \pi_{o}$.

\subsection{Individual behaviour, maximum likelihood estimation}

To investigate a preference for combining good with bad or good with good further we perform a maximum likelihood estimation where we test the frequencies of combinations of second and fourth order risk attitudes. A subject is risk averse and temperate if they have a preference for combining good with bad, risk loving and intemperate if they have a preference for combining good with bad, and risk neutral 
and temperance neutral otherwise. There are a total of nine possible combinations of second and fourth order risk attitudes. We denote these different types as $\pi_{a, b}$, $a, b \in\{s, n, o\}$ where $a$ indicates whether the second order risk attitude satisfies risk apportionment of order 2 (risk aversion), matches the opposite preference (risk loving preferences) or is neutral toward risk apportionment of order 2 (risk neutral) and $b$ indicates whether the fourth order risk attitude satisfies fourth order risk apportionment (temperance), matches the opposite attitude (intemperance) or is neutral (temperance neutral).

We again allow for errors which differ across types and orders of risk attitudes. A risk averse subject is assumed to have a probability $v$ of mistakenly choosing the riskier option, a risk loving subject has a probability $\theta$ of mistakenly choosing the safer option, and a risk neutral subject chooses either option with probability $1 / 2$. Temperate subjects are assumed to mistakenly choose the intemperate option with probability $\omega$, intemperate subjects mistakenly choose the temperate option with probability $\zeta$, and temperance neutral subjects choose either option with probability $1 / 2$. The estimated proportions are presented in Figure 4 for losses, Figure 5 for 50-50 gains and Figure 6 for small probability gains.

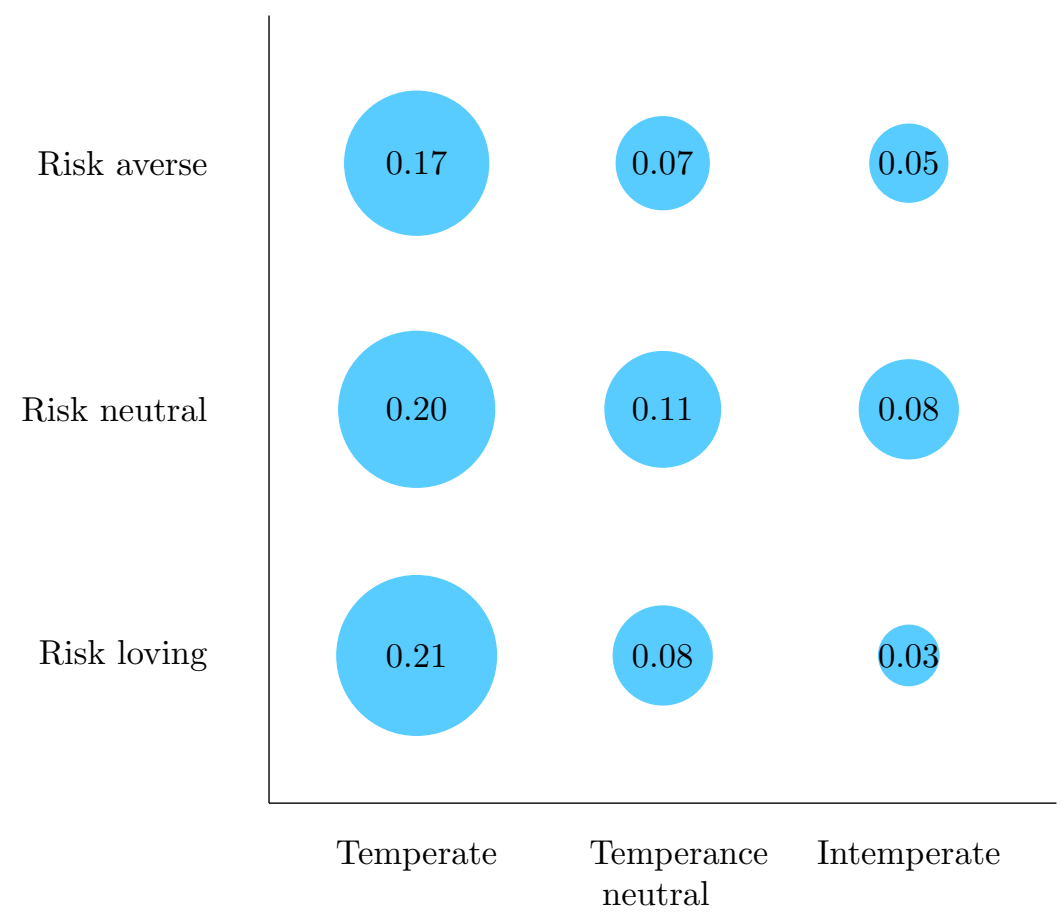

Figure 4: Maximum likelihood estimations of combinations of second and fourth order risk attitudes, loss treatment, with an estimated error rate for risk averse subjects $\hat{v}=0.04$, for risk loving subjects $\hat{\theta}=0.05$, for temperate subjects $\hat{\omega}=0.04$ and for intemperate subjects $\hat{\zeta}=0.01$. 


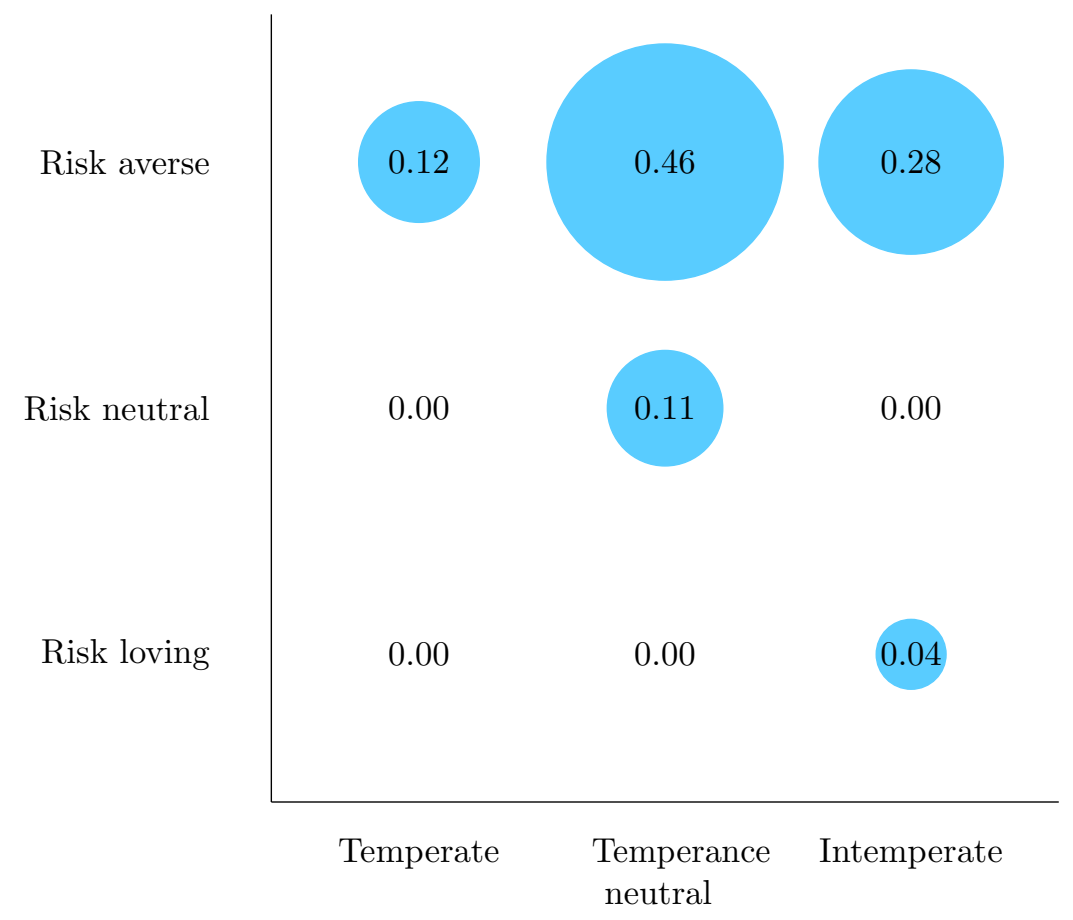

Figure 5: Maximum likelihood estimations of combinations of second and fourth order risk attitudes, 50-50 gain treatment, with an estimated error rate for risk averse subjects $\hat{v}=0.09$, for risk loving subjects $\hat{\theta}=0.05$, for temperate subjects $\hat{\omega}=0.04$ and for intemperate subjects $\hat{\zeta}=0.04$.

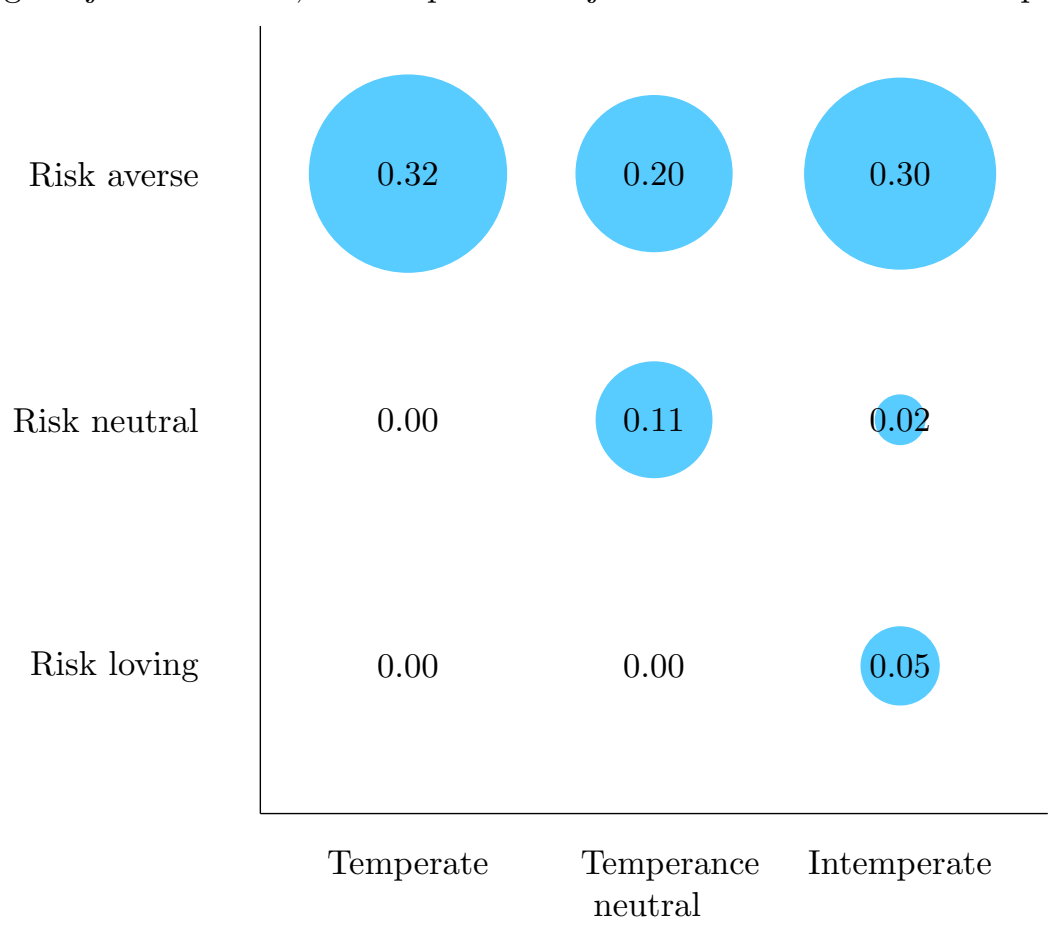

Figure 6: Maximum likelihood estimations of combinations of second and fourth order risk attitudes, small probability gain treatment, with an estimated error rate for risk averse subjects $\hat{v}=0.04$, for risk loving subjects $\hat{\theta}=0.06$, for temperate subjects $\hat{\omega}=0.06$ and for intemperate subjects $\hat{\zeta}=0.02$. 
If subjects have a preference for combining good with bad or good with good then the symmetric types $\left(\pi_{s, s}, \pi_{n, n}, \pi_{o, o}\right)$ should be most common. This means that most of the mass should be on the diagonals in Figures 4, 5 and 6 . The data does not show such a pattern. For losses, the two most common types in fact combine temperance with a risk loving attitude and with risk neutrality. For 50-50 gains, the two most frequent types combine risk aversion with temperance neutrality and risk aversion with intemperance. For small probability gains the most common type combines risk aversion with temperance, in agreement with a preference for combining good with bad, but the second most common type, with a share of $30 \%$ of the subjects, combines risk aversion with intemperance, and the difference in the proportions of these two types is small.

To formally test the hypothesis of a preference for combining good with bad or good with good for gains and losses we test whether $\pi_{s, s}+\pi_{o, o}=\pi_{s, o}+\pi_{o, s}$ against the alternative that $\pi_{s, s}+\pi_{o, o} \neq \pi_{s, o}+\pi_{o, s}$ using a (log) likelihood ratio test. We do not include the proportion of neutral types in the test as subjects may be classified as indifferent because they are confused, distracted or inattentive and the extent of this may depend on the order of the risk preference measured. Neither for losses (LR 0.892, p-value 0.345), nor for 50-50 gains (LR 1.923, $p$-value 0.166 ) nor for small probability gains (LR 0.400, $p$-value 0.527 ) can we reject that $\pi_{s, s}+\pi_{o, o}=\pi_{s, o}+\pi_{o, s}$. Thus, we do not find evidence that risk aversion is combined more often with temperance than intemperance or that risk lovers are more likely to be intemperate than temperate for gains or losses.

\section{Discussion}

The aggregate pattern of risk aversion, prudence and slight intemperance found for pure gains in our experiment mirrors earlier findings of Deck and Schlesinger (2010) and Baillon et al. (2017b). Deck and Schlesinger (2014), Ebert and Wiesen (2014) and Noussair et al. (2014) also find risk aversion and prudence in the aggregate, but find moderate temperance rather than intemperance. Deck and Schlesinger (2014) point out that the modest intemperance of Deck and Schlesinger (2010) can be explained if there were unusually many risk lovers in their sample, but could not verify this explanation as Deck and Schlesinger (2010) collected no information on second order risk attitudes. The aggregate intemperance in our sample does not appear to be caused by intemperate risk lovers. The number of risk lovers is small in the gain treatments and we do not find evidence that fourth order risk preferences are a function of second order risk preferences. Baillon et al. (2017b) also have few 
risk lovers in their sample while finding intemperance. The respective temperance or intemperance is quite weak at the aggregate level in all studies, suggesting that the observed discrepancies may simply be the consequence of differences in the make-up of samples combined with modest effects from differences in presentation.

Although a preference for combining good with bad or good with good seems to explain higher order risk preferences for mixed lotteries, our results indicate this is not the case for pure gains or losses. We do not find evidence at the individual level that risk aversion is combined with temperance, and the imprudence we find for losses, as well as the combination of risk aversion and intemperance for gains, is evidence against the hypothesis. Whether the differences between earlier findings and ours can be explained by loss aversion, by people having different preferences for mixed lotteries than for pure gains or losses or by people using different heuristics between these domains is a question that deserves attention in future studies.

In contrast to Deck and Schlesinger (2010) and Maier and Rüger (2012), we find strong reference dependence for higher order risk preferences. As per the usual findings, the loss frame induces much more risk loving preferences. We find that prudence and temperance are also affected: preferences shift from prudence and intemperance under gains to imprudence and temperance under losses. Thus, we have a full reversal of higher order risk attitudes: risk aversion, prudence, and intemperance under gains, risk loving preferences, imprudence, and temperance under losses. This is consistent with reflection (Kahneman and Tversky, 1979), where risk preferences are reversed under losses. The different findings suggest it should be worthwhile to investigate reference dependence further in the context of higher order risk preferences.

Prospect theory (Tversky and Kahneman, 1992) has been suggested as an explanation of findings of higher order risk preferences (Deck and Schlesinger, 2010). Reference dependence is an important component of prospect theory, which can explain the differences in higher order risk preferences between the gain and loss treatments. The other important component of prospect theory is inverse-S shaped probability weighting, which leads to risk loving behaviour for small probability gains. We do not find the predicted behaviour: choices in the small probability gain treatment closely resemble those in the 50-50 gain treatment, meaning, in particular, that we observe strong risk aversion. A possible explanation for the observed risk aversion in the small probability gains treatment is that the probability weighting function is convex, rather than inverse-S shaped. Convex probability weighting for gains has been found in some experiments, e.g. Van de Kuilen and Wakker (2011). 


\section{Conclusion}

It is well-established that second order risk attitudes for gains are the mirror image of those for losses. In an experiment, we observe the reflection effect also for higher order risk preferences. We find prudence for gains but imprudence for losses and intemperance for gains but temperance for losses. This reflection affects the external validity of higher order risk preferences measured under gains only, and has behavioural implications when choices involve losses.

The recent literature has found evidence for the hypothesis that higher order risk preferences are generated by a preference for combining good with bad or good with good. Such a preference implies risk aversion should be combined with temperance, and that all decision makers should be prudent. However, we find that correlations between the number of risk averse choices and the number of temperate choices are small and insignificant. Furthermore, the imprudence we find as the majority preference for losses, and the simultaneous preference for risk aversion and intemperance on the aggregate level in the gain domain, are evidence against this hypothesis for pure gains and pure losses. 


\section{Appendix A Proof that probabilistic mixture pre- serves stochastic dominance}

We follow the definition of stochastic dominance of Eeckhoudt et al. (2009). It is assumed that all random variables have bounded supports contained in $[l, u]$. With $F^{(0)}(x)$ the cumulative distribution function of distribution $F$, they define $F^{(i)}(x) \equiv \int_{l}^{x} F^{(i-1)}(t) d t$ for $i \geq 1$. Distribution $F$ weakly dominates distribution $G$ through $N$-th order stochastic dominance if i) $F^{(N-1)}(x) \leq G^{(N-1)}(x)$ for all $l \leq x \leq u$ and ii) $F^{(i)}(u) \leq G^{(i)}(u)$ for $i=1, \ldots, N$.

We will show that if distribution $F$ dominates distribution $G$ through $N$-th order stochastic dominance, then the probabilistic mixture $F^{\prime}$ of distribution $F$ and distribution $H$ dominates probabilistic mixture $G^{\prime}$ of distribution $G$ and distribution $H$ through $N$-th order stochastic dominance.

The cumulative distribution function $F^{(0)}(x)$ can be written as $\lambda F^{(0)}(x)+(1-$ $\lambda) H^{(0)}(x), \lambda \in[0,1]$. Similarly, $G^{(0)}(x) \equiv \lambda G^{(0)}(x)+(1-\lambda) H^{(0)}(x)$. Then

$$
F^{\prime(1)}(x)=\lambda \int_{l}^{x} F^{(0)}(t) d t+(1-\lambda) \int_{l}^{x} H^{(0)}(t) d t=\lambda F^{(1)}(x)+(1-\lambda) H^{(1)}(x)
$$

and

$$
G^{\prime(1)}(x)=\lambda \int_{l}^{x} G^{(0)}(t) d t+(1-\lambda) \int_{l}^{x} H^{(0)}(t) d t=\lambda G^{(1)}(x)+(1-\lambda) H^{(1)}(x)
$$

for all $l \leq x \leq u$.

Furthermore, if

$$
F^{\prime(i-1)}(x)=\lambda F^{(i-1)}(x)+(1-\lambda) H^{(i-1)}(x)
$$

then

$$
F^{\prime(i)}(x)=\lambda \int_{l}^{x} F^{(i-1)}(t) d t+(1-\lambda) \int_{l}^{x} H^{(i-1)}(t) d t=\lambda F^{(i)}(x)+(1-\lambda) H^{(i)}(x)
$$

and if

$$
G^{\prime(i-1)}(x)=\lambda G^{(i-1)}(x)+(1-\lambda) H^{(i-1)}(x)
$$

then

$$
G^{(i)}(x)=\lambda \int_{l}^{x} G^{(i-1)}(t) d t+(1-\lambda) \int_{l}^{x} H^{(i-1)}(t) d t=\lambda G^{(i)}(x)+(1-\lambda) H^{(i)}(x)
$$


Thus, by induction

$$
F^{\prime(i)}(x)=\lambda F^{(i)}(x)+(1-\lambda) H^{(i)}(x)
$$

and

$$
G^{(i)}(x)=\lambda G^{(i)}(x)+(1-\lambda) H^{(i)}(x)
$$

for all $i \geq 0$ and all $l \leq x \leq u$.

If distribution $F$ dominates distribution $G$ through $N$-th order stochastic dominance, i.e. $F^{(N-1)}(x) \leq G^{(N-1)}(x)$ for all $l \leq x \leq u$ and $F^{(i)}(u) \leq G^{(i)}(u)$ for $i=1, \ldots, N$, then $F^{\prime(N-1)}(x) \leq G^{\prime(N-1)}(x)$ for all $l \leq x \leq u$ and $F^{\prime(i)}(u) \leq G^{\prime(i)}(u)$ for $i=1, \ldots, N$, and distribution $F^{\prime}$ stochastically dominates distribution $G^{\prime}$ through $N$-th order stochastic dominance. 


\section{Appendix B Instructions}

You have been given $€ 15$. This will be your compensation for participating in the experiment. On the next pages, you will be presented with several choice questions, each of which consists of two options. At the end of the experiment, you will randomly select one question by rolling dice (each question is equally likely to be selected). The option you've chosen in that question will be played out for real: You will be paid or you will have to pay the corresponding monetary amounts. The average payment additional to the $€ 15$ you've been given is zero. For all options in this questionnaire, the final outcome (a monetary payment) depends on the colour of tokens drawn from one or more bags.

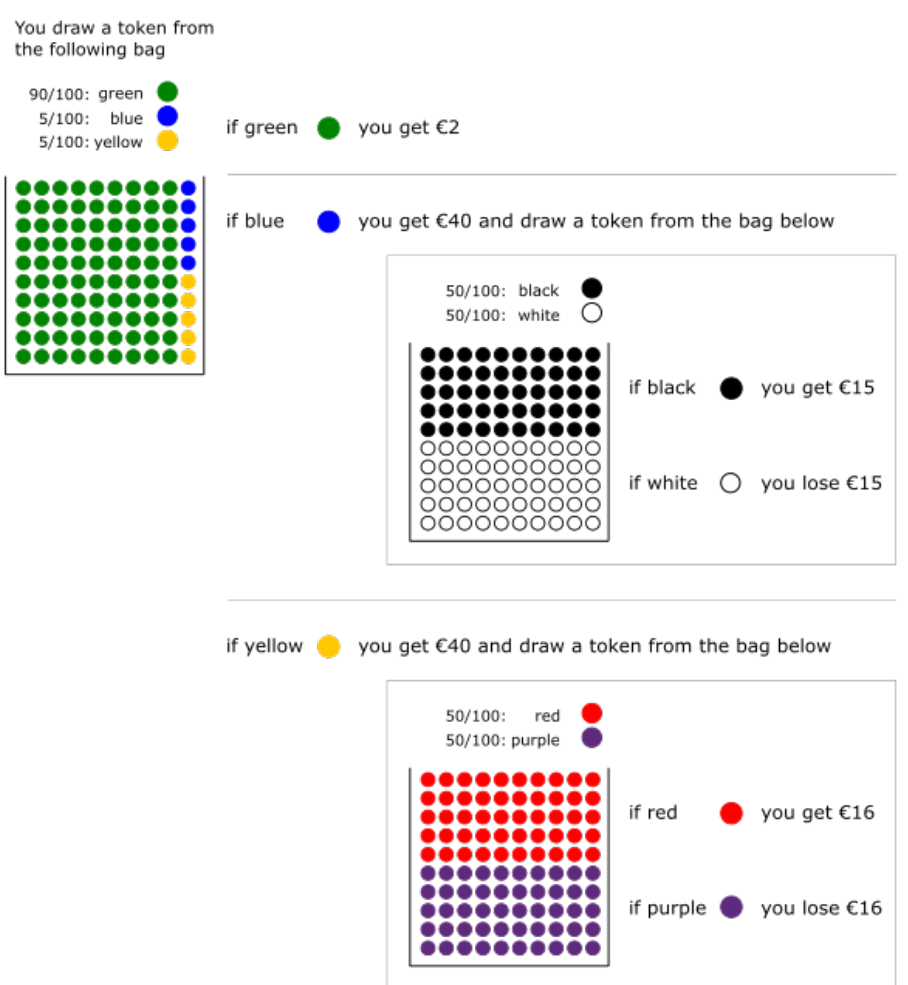

For example, in the image to the left, if you draw a green token, you get $€ 2$. If you draw a blue token, you must draw another token from a bag with 50 black and 50 white tokens. If that token is black, you get $€ 40+€ 15=€ 55$. If it is white you get $€ 40-€ 15$ $=€ 25$. If you draw a yellow token, you must draw another token from a bag with 50 red and 50 purple tokens. If it is red, you get $€ 40+€ 16=€ 56$. If it is purple, you get $€ 40-€ 16$ $=€ 24$. 
Appendix C Task screenshot
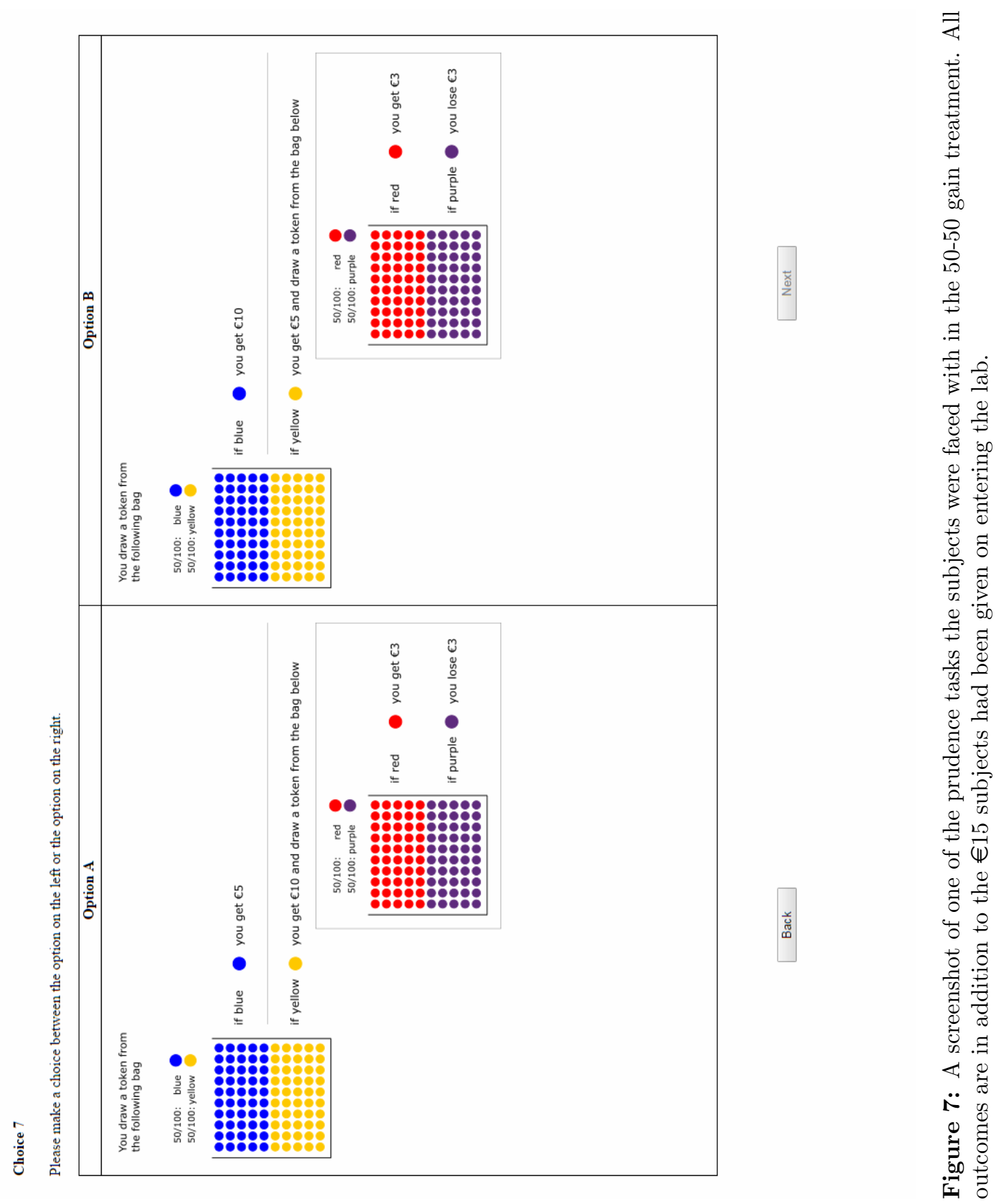


\section{Appendix D Tasks}

Table 5: Tasks for the loss treatment

\begin{tabular}{|c|c|c|c|c|}
\hline \multirow[b]{2}{*}{ Task } & \multicolumn{2}{|c|}{$\begin{array}{l}\text { Risk averse option } \\
\qquad[g, a]\end{array}$} & \multicolumn{2}{|c|}{$\begin{array}{l}\text { Risk loving option } \\
\qquad[e, t]\end{array}$} \\
\hline & $-g$ & $-a$ & $-e$ & $-t$ \\
\hline 1 & 8 & 9 & 4 & 13 \\
\hline 2 & 7 & 8 & 1 & 14 \\
\hline 3 & 8 & 10 & 4 & 14 \\
\hline 4 & 7 & 9 & 3 & 13 \\
\hline 5 & 5 & 6 & 1 & 10 \\
\hline 6 & 6 & 8 & 3 & 11 \\
\hline 7 & 7 & 9 & 4 & 12 \\
\hline 8 & 6 & 7 & 1 & 12 \\
\hline 9 & 6 & 8 & 1 & 13 \\
\hline 10 & 7 & 9 & 2 & 14 \\
\hline 11 & 6 & 10 & 2 & 14 \\
\hline 12 & 6 & 8 & 2 & 12 \\
\hline
\end{tabular}

\begin{tabular}{lccc} 
& \multicolumn{2}{c}{$[a, g+\tilde{\varepsilon}]$} & {$[g, a+\tilde{\varepsilon}]$} \\
\cline { 2 - 4 } Task & $\tilde{\varepsilon}$ & $-a$ & $-g$ \\
1 & {$[4,-4]$} & 9 & 6 \\
2 & {$[3,-3]$} & 10 & 4 \\
3 & {$[4,-4]$} & 8 & 5 \\
4 & {$[2,-2]$} & 6 & 4 \\
5 & {$[4,-4]$} & 10 & 5 \\
6 & {$[3,-3]$} & 9 & 4 \\
7 & {$[5,-5]$} & 9 & 7 \\
8 & {$[3,-3]$} & 8 & 4 \\
9 & {$[4,-4]$} & 9 & 5 \\
10 & {$[2,-2]$} & 8 & 4 \\
11 & {$[1,-1]$} & 7 & 2 \\
12 & {$[2,-2]$} & 10 & 3 \\
\hline
\end{tabular}

All amounts are in Euro 
Temperate option Intemperate option

\begin{tabular}{lccc} 
& {$\left[w+\tilde{\varepsilon}_{1}, w+\tilde{\varepsilon}_{2}\right]$} & {$\left[w, w+\tilde{\varepsilon}_{1}+\tilde{\varepsilon}_{2}\right]$} \\
\cline { 2 - 4 } Task & $\tilde{\varepsilon}_{1}$ & $\tilde{\varepsilon}_{2}$ & $-w$ \\
1 & {$[2,-2]$} & {$[4,-4]$} & 8 \\
2 & {$[1,-1]$} & {$[4,-4]$} & 7 \\
3 & {$[2,-2]$} & {$[3,-3]$} & 6 \\
4 & {$[2,-2]$} & {$[2,-2]$} & 9 \\
5 & {$[1,-1]$} & {$[5,-5]$} & 7 \\
6 & {$[3,-3]$} & {$[3,-3]$} & 7 \\
7 & {$[2,-2]$} & {$[3,-3]$} & 9 \\
8 & {$[1,-1]$} & {$[2,-2]$} & 8 \\
9 & {$[2,-2]$} & {$[3,-3]$} & 7 \\
10 & {$[2,-2]$} & {$[3,-3]$} & 8 \\
11 & {$[1,-1]$} & {$[1,-1]$} & 6 \\
12 & {$[1,-1]$} & {$[3,-3]$} & 8 \\
\hline \multicolumn{3}{r}{ All amounts are in Euro }
\end{tabular}

Table 6: Tasks for the 50-50 gain treatment

\begin{tabular}{lcccc}
\hline & \multicolumn{2}{c}{$\begin{array}{c}\text { Risk averse option } \\
{[a, g]}\end{array}$} & \multicolumn{2}{c}{ Risk loving option } \\
Task & $a$ & $g$ & $t$ & $e$ \\
1 & 8 & 9 & 1 & 16 \\
2 & 7 & 9 & 2 & 14 \\
3 & 9 & 11 & 4 & 16 \\
4 & 7 & 9 & 3 & 13 \\
5 & 4 & 5 & 1 & 8 \\
6 & 5 & 7 & 2 & 10 \\
7 & 6 & 7 & 3 & 10 \\
8 & 7 & 9 & 4 & 12 \\
9 & 6 & 8 & 3 & 11 \\
10 & 8 & 9 & 5 & 12 \\
11 & 8 & 9 & 3 & 14 \\
12 & 6 & 7 & 1 & 12 \\
\hline
\end{tabular}

All amounts are in Euro 
Prudent option Imprudent option

\begin{tabular}{lccl} 
& \multicolumn{2}{c}{$[a, g+\tilde{\varepsilon}]$} & {$[g, a+\tilde{\varepsilon}]$} \\
\cline { 2 - 4 } Task & $\tilde{\varepsilon}$ & $g$ & $a$ \\
1 & {$[3,-3]$} & 11 & 4 \\
2 & {$[2,-2]$} & 9 & 3 \\
3 & {$[4,-4]$} & 8 & 5 \\
4 & {$[3,-3]$} & 10 & 5 \\
5 & {$[1,-1]$} & 8 & 3 \\
6 & {$[4,-4]$} & 9 & 5 \\
7 & {$[5,-5]$} & 12 & 6 \\
8 & {$[5,-5]$} & 10 & 6 \\
9 & {$[4,-4]$} & 10 & 5 \\
10 & {$[3,-3]$} & 6 & 4 \\
11 & {$[1,-1]$} & 6 & 2 \\
12 & {$[2,-2]$} & 6 & 3 \\
\hline
\end{tabular}

Temperate option Intemperate option

\begin{tabular}{lccc} 
& {$\left[w+\tilde{\varepsilon}_{1}, w+\tilde{\varepsilon}_{2}\right]$} & {$\left[w, w+\tilde{\varepsilon}_{1}+\tilde{\varepsilon}_{2}\right]$} \\
\cline { 2 - 4 } Task & $\tilde{\varepsilon}_{1}$ & $\tilde{\varepsilon}_{2}$ & $w$ \\
1 & {$[2,-2]$} & {$[4,-4]$} & 7 \\
2 & {$[3,-3]$} & {$[3,-3]$} & 7 \\
3 & {$[1,-1]$} & {$[2,-2]$} & 5 \\
4 & {$[1,-1]$} & {$[3,-3]$} & 5 \\
5 & {$[2,-2]$} & {$[3,-3]$} & 8 \\
6 & {$[2,-2]$} & {$[6,-6]$} & 9 \\
7 & {$[3,-3]$} & {$[4,-4]$} & 8 \\
8 & {$[2,-2]$} & {$[5,-5]$} & 8 \\
9 & {$[3,-3]$} & {$[6,-6]$} & 10 \\
10 & {$[4,-4]$} & {$[5,-5]$} & 10 \\
11 & {$[1,-1]$} & {$[6,-6]$} & 8 \\
12 & {$[2,-2]$} & {$[2,-2]$} & 5 \\
\hline
\end{tabular}

All amounts are in Euro 
Table 7: Tasks for the small probability treatment

\begin{tabular}{|c|c|c|c|c|c|c|}
\hline \multirow[b]{2}{*}{ Task } & \multicolumn{3}{|c|}{$\begin{array}{c}\text { Risk averse option } \\
(p: g, p: a, 1-2 p: y)\end{array}$} & \multicolumn{3}{|c|}{$\begin{array}{c}\text { Risk loving option } \\
(p: e, p: t, 1-2 p: y)\end{array}$} \\
\hline & $g$ & $a$ & $e$ & $t$ & $y$ & $p$ \\
\hline 1 & 70 & 46 & 100 & 16 & 2 & 0.08 \\
\hline 2 & 38 & 28 & 60 & 6 & 2 & 0.09 \\
\hline 3 & 60 & 48 & 86 & 22 & 2 & 0.07 \\
\hline 4 & 35 & 32 & 52 & 15 & 1 & 0.06 \\
\hline 5 & 110 & 90 & 180 & 20 & 1 & 0.05 \\
\hline 6 & 40 & 35 & 70 & 5 & 2 & 0.05 \\
\hline 7 & 30 & 24 & 48 & 6 & 1 & 0.04 \\
\hline 8 & 66 & 62 & 120 & 8 & 2 & 0.04 \\
\hline 9 & 58 & 44 & 90 & 12 & 2 & 0.03 \\
\hline 10 & 180 & 144 & 280 & 44 & 1 & 0.02 \\
\hline 11 & 70 & 54 & 110 & 14 & 1 & 0.01 \\
\hline \multirow[t]{2}{*}{12} & 50 & 40 & 80 & 10 & 1 & 0.10 \\
\hline & $\begin{array}{r}\mathrm{P} \\
(p: a, 1 \\
\end{array}$ & $\begin{array}{l}\text { lent o } \\
+\tilde{\varepsilon}\end{array}$ & $: y)$ & & den & $o: y)$ \\
\hline Task & $\tilde{\varepsilon}$ & $g$ & $a$ & & $y$ & $p$ \\
\hline 1 & {$[15,-15]$} & 50 & 20 & & 1 & 0.07 \\
\hline 2 & {$[16,-16]$} & 80 & 22 & & 1 & 0.08 \\
\hline 3 & {$[25,-25]$} & 70 & 30 & & 1 & 0.09 \\
\hline 4 & {$[24,-24]$} & 60 & 30 & & 2 & 0.05 \\
\hline 5 & {$[50,-50]$} & 96 & 54 & & 2 & 0.05 \\
\hline 6 & {$[46,-46]$} & 100 & 60 & & 1 & 0.04 \\
\hline 7 & {$[38,-38]$} & 88 & 42 & & 2 & 0.03 \\
\hline 8 & {$[20,-20]$} & 64 & 34 & & 2 & 0.02 \\
\hline 9 & {$[45,-45]$} & 125 & 60 & & 2 & 0.02 \\
\hline 10 & {$[30,-30]$} & 150 & 55 & & 2 & 0.01 \\
\hline 11 & {$[28,-28]$} & 60 & 40 & & 1 & 0.10 \\
\hline 12 & {$[32,-32]$} & 75 & 44 & & 1 & 0.06 \\
\hline
\end{tabular}

All amounts are in Euro 
Temperate option

Intemperate option

\begin{tabular}{lccccc} 
& \multicolumn{4}{c}{$\left(p: w+\tilde{\varepsilon}_{1}, p: w+\tilde{\varepsilon}_{2}, 1-2 p: y\right)$} & $\left(p: w, p: w+\tilde{\varepsilon}_{1}+\tilde{\varepsilon}_{2}, 1-2 p: y\right)$ \\
\cline { 2 - 7 } Task & $\tilde{\varepsilon}_{1}$ & $\tilde{\varepsilon}_{2}$ & $w$ & $y$ & $p$ \\
1 & {$[20,-20]$} & {$[45,-45]$} & 70 & 1 & 0.04 \\
2 & {$[28-28]$} & {$[30,-30]$} & 70 & 2 & 0.05 \\
3 & {$[24,-24]$} & {$[36,-36]$} & 65 & 2 & 0.05 \\
4 & {$[14,-14]$} & {$[14,-14]$} & 32 & 2 & 0.06 \\
5 & {$[22,-22]$} & {$[26,-26]$} & 60 & 2 & 0.06 \\
6 & {$[25,-25]$} & {$[30,-30]$} & 75 & 1 & 0.07 \\
7 & {$[10,-10]$} & {$[20,-20]$} & 35 & 1 & 0.08 \\
8 & {$[30,-30]$} & {$[50,-50]$} & 100 & 1 & 0.03 \\
9 & {$[34,-34]$} & {$[40,-40]$} & 85 & 2 & 0.02 \\
10 & {$[18,-18]$} & {$[42,-42]$} & 68 & 1 & 0.01 \\
11 & {$[5,-5]$} & {$[38,-38]$} & 55 & 1 & 0.10 \\
12 & {$[14,-14]$} & {$[34,-34]$} & 58 & 2 & 0.04 \\
\hline
\end{tabular}

All amounts are in Euro

\section{Appendix E Frequency Tables}

Table 8: Frequency table second and fourth order risk preferences, losses

\begin{tabular}{lcccc}
\hline & Temperate & Temperance neutral & Intemperate & Total \\
\hline Risk averse & 21 & 9 & 6 & 36 \\
Risk neutral & 23 & 14 & 10 & 47 \\
Risk loving & 25 & 10 & 4 & 39 \\
\hline Total & 69 & 33 & 20 & 122 \\
\hline
\end{tabular}

Table 9: Frequency table second and fourth order risk preferences, 50-50 gains

\begin{tabular}{lcccc}
\hline & Temperate & Temperance neutral & Intemperate & Total \\
\hline Risk averse & 5 & 22 & 14 & 41 \\
Risk neutral & 2 & 10 & 4 & 16 \\
Risk loving & 0 & 1 & 2 & 3 \\
\hline Total & 7 & 33 & 20 & 60 \\
\hline
\end{tabular}


Table 10: Frequency table second and fourth order risk preferences, small probability gains

\begin{tabular}{lcccc}
\hline & Temperate & Temperance neutral & Intemperate & Total \\
\hline Risk averse & 19 & 13 & 18 & 50 \\
Risk neutral & 0 & 7 & 2 & 9 \\
Risk loving & 0 & 0 & 3 & 3 \\
\hline Total & 19 & 20 & 23 & 62 \\
\hline
\end{tabular}

\section{References}

Attema, A. E., l'Haridon, O., and Van de Kuilen, G. (2017). Multivariate risk preferences for health and wealth. Working paper.

Baillon, A. (2017). Prudence with respect to ambiguity. Economic Journal, 127(604):1731-1755.

Baillon, A., Bleichrodt, H., and Spinu, V. (2017a). Searching for the reference point. Working paper, Erasmus University Rotterdam.

Baillon, A., Schlesinger, H., and Van de Kuilen, G. (2017b). Measuring higher order ambiguity preferences. Experimental Economics, 21(2):233-256.

Browning, M. and Lusardi, A. (1996). Household saving: Micro theories and micro facts. Journal of Economic Literature, 34(4):1797-1855.

Carroll, C. D. and Samwick, A. A. (1998). How important is precautionary saving? Review of Economics and Statistics, 80(3):410-419.

Crainich, D., Eeckhoudt, L., and Trannoy, A. (2013). Even (mixed) risk lovers are prudent. American Economic Review, 103(4):1529-1535.

Deck, C. and Schlesinger, H. (2010). Exploring higher order risk effects. Review of Economic Studies, 77(4):1403-1420.

Deck, C. and Schlesinger, H. (2014). Consistency of higher order risk preferences. Econometrica, 82(5):1913-1943.

Deck, C. and Schlesinger, H. (2017). On the robustness of higher order risk preferences. Journal of Risk and Insurance, 85(2):313-333. 
Drèze, J. H. and Modigliani, F. (1972). Consumption decisions under uncertainty. Journal of Economic Theory, 5(3):308-335.

Ebert, S. (2016). Decision making when things are only a matter of time. Working paper.

Ebert, S. and Wiesen, D. (2011). Testing for prudence and skewness seeking. Management Science, 57(7):1334-1349.

Ebert, S. and Wiesen, D. (2014). Joint measurement of risk aversion, prudence, and temperance. Journal of Risk and Uncertainty, 48(3):231-252.

Eeckhoudt, L. and Gollier, C. (2005). The impact of prudence on optimal prevention. Economic Theory, 26(4):989-994.

Eeckhoudt, L., Rey, B., and Schlesinger, H. (2007). A good sign for multivariate risk taking. Management Science, 53(1):117-124.

Eeckhoudt, L. and Schlesinger, H. (2006). Putting risk in its proper place. American Economic Review, 96(1):280-289.

Eeckhoudt, L. and Schlesinger, H. (2013). Handbook of Insurance, chapter HigherOrder Risk Attitudes, pages 41-57. Springer Science+Business Media New York.

Eeckhoudt, L., Schlesinger, H., and Tsetlin, I. (2009). Apportioning of risks via stochastic dominance. Journal of Economic Theory, 144(3):994-1003.

Eső, P. and White, L. (2004). Precautionary bidding in auctions. Econometrica, $72(1): 77-92$.

Etchart-Vincent, N. and l'Haridon, O. (2011). Monetary incentives in the loss domain and behavior toward risk: An experimental comparison of three reward schemes including real losses. Journal of Risk and Uncertainty, 42(1):61-83.

Fei, W. and Schlesinger, H. (2008). Precautionary insurance demand with statedependent background risk. Journal of Risk and Insurance, 75(1):1-16.

Gollier, C. and Pratt, J. W. (1996). Risk vulnerability and the tempering effect of background risks. Econometrica, 64(5):1109-1123.

Haering, A., Heinrich, T., and Mayrhofer, T. (2017). Exploring the consistency of higher-order risk preferences. Working Paper, Ruhr Economic Papers, No. 688. 
Kahneman, D. (2003). Maps of bounded rationality: psychology for behavioral economics. American Economic Review, 93(5):1449-1475.

Kahneman, D. and Tversky, A. (1979). Prospect theory: An analysis of decision under risk. Econometrica, 47(2):263-292.

Kőszegi, B. and Rabin, M. (2006). A model of reference-dependent preferences. Quarterly Journal of Economics, 121(4):1133-1165.

Kimball, M. S. (1990). Precautionary saving in the small and in the large. Econometrica, 58(1):53-73.

Kimball, M. S. (1992). Precautionary motives for holding assets. In Newman, P. K., Milgate, M., and Eatwell, J., editors, The New Palgrave Dictionary of Money and Finance, volume 3, pages 158-163. London: MacMillan.

Leland, H. E. (1968). Saving and uncertainty: The precautionary demand for saving. Quarterly Journal of Economics, 82(3):465-473.

Maier, J. and Rüger, M. (2012). Experimental evidence on higher-order risk preferences with real monetary losses. Working paper.

Menezes, C., Geiss, C., and Tressler, J. (1980). Increasing downside risk. American Economic Review, 70(5):921-932.

Noussair, C. N., Trautmann, S. T., and Van de Kuilen, G. (2014). Higher order risk attitudes, demographics, and financial decisions. Review of Economic Studies, $81(1): 325-355$.

Peter, R. (2017). Optimal self-protection in two periods: On the role of endogenous saving. Journal of Economic Behavior \& Organization, 137:19-36.

Pratt, J. W. and Zeckhauser, R. J. (1987). Proper risk aversion. Econometrica, $55(1): 143-154$.

Sandmo, A. (1970). The effect of uncertainty on saving decisions. Review of Economic Studies, 37(3):353-360.

Trautmann, S. T. and Van de Kuilen, G. (2018). Higher order risk attitudes: A review of experimental evidence. European Economic Review. Advance online publication. 
Tversky, A. and Kahneman, D. (1992). Advances in Prospect Theory: Cumulative representation of uncertainty. Journal of Risk and Uncertainty, 5(4):297-323.

Van de Kuilen, G. and Wakker, P. P. (2011). The midweight method to measure attitudes toward risk and ambiguity. Management Science, 57(3):582-598. 